\title{
Shasira Craft, Usaha Kerajinan Kain Perca Sasirangan Sebagai Upaya Pemberdayaan Ibu-Ibu Warga Perumahan Seribu, Kecamatan Martapura, Kabupaten Banjar, Provinsi Kalimantan Selatan
}

\author{
Mayang Gadih Ranti1 , Erni Susilawati² \\ Pendidikan Matematika, STKIP PGRI Banjarmasin \\ Jl. Sultan Adam RT 23 No. 18, Banjarmasin, Kalimantan Selatan, Indonesia \\ 1 mayanggadih@stkipbjm.ac.id \\ Pendidikan Bahasa dan Sastra Indonesia, STKIP PGRI Banjarmasin \\ Jl. Sultan Adam RT 23 No. 18, Banjarmasin, Kalimantan Selatan, Indonesia \\ 2ernisusilawati1975@gmail.com
}

Artikel diterima: 06-09-2019, direvisi: 10-11-2019, diterbitkan: 25-12-2019

\begin{abstract}
Abstrak
Kain Sasirangan adalah Kain Khas Kalimantan Selatan. Tingginya minat penggunaan Kain Sasirangan oleh masyarakat Kalimantan Selatan mendorong menjamurnya rumah industri dan jahit kain sasirangan. Permasalahan muncul ketika banyak limbah kain perca kain sasirangan yang dihasilkan. Kain perca sasirangan banyak terbuang tanpa dimanfaatkan kembali. Padahal jika dimanfaatkan dapat diolah menjadi produk-produk yang bernilai seni dan jual yang tinggi. Di sisi lain, sekelompok Ibu-lbu yang memiliki banyak waktu luang dan memiliki hasrat untuk meningkatkan pendapatan keluarga, seperti Ibu-ibu kelompok Yasinan Mushala Nurul Iman di Perumahan Seribu, Martapura, dapat diberdayakan. Pemberdayaan Ibu-lbu kelompok Yasinan dilakukan melalui Kegiatan pelatihan dan pendampingan pengolahan limbah kain perca sasirangan menjadi produk-produk seperti tas, kantong HP, aksesoris, bros, peci, toples cantik dan lain-lain. Hal ini dilakukan guna memberi bekal wawasan kepada Ibu-Ibu dalam berwirausaha guna membuka lapangan kerja baru dengan memanfaatkan sumber daya yang ada. Kegiatan ini dilakukan sebanyak 7 (tujuh) kali pertemuan dimana pada setiap pertemuan Ibu-lbu peserta kegiatan pelatihan dibimbing dan diarahkan langsung oleh instruktur untuk mulai dari cara mengolah kain perca sasirangan menjadi berbagai produk yang menarik, hingga kegiatan pengemasan, pemberian merk Shasira Craft dan pemasaran.
\end{abstract}

Kata Kunci: Kain Perca Sasirangan, Kerajinan Tangan, Martapura. 


\begin{abstract}
Sasirangan is the icon of South Kalimantan. High of the use of Sasirangan by South Kalimantan People make the Sasirangan fabric and home industry blooms everywhere. The problem is the waste of Sasirangan patchwork resulted. Sasirangan Patchwork come without recycled. Even though, if the Sasirangan Patchwork can be recycled, it will be an interesting and commercial product. On the other sides, there are a group of women in Perumahan Seribu,Martapura who has many leisure time but also willing to increase family income, likes the member of recitation group Mushala Nurul Iman. They can process the waste of Sasirangan Patchwork become an interesting products, like bags, Hand phone Pocket, Brooch, Accessories, cap, beautiful jar and etc. The Training Program can open insight and give a skill to being entrepreneur and make a new job field using available resources. The Program was held in seven meetings. In every meeting, the participant was guided by a competence instructor to make a product of Sasirangan patchwork, from the making, packing, labeling and marketing.
\end{abstract}

Keywords: Handicraft, Sasirangan Pathcwork, Martapura.

\section{Pendahuluan}

Kain Sasirangan adalah Kain Khas Kalimantan Selatan. Kain Sasirangan berasal dari istilah dalam bahasa Banjar, yaitu Sirang atau manyirang yang berarti menjelulur, yaitu kain dijahit dengan tangan dan ditarik benangnya. Proses pengerjaan kain ini dilakukan dengan cara menjelujur kemudian diikat ditali lalu dicelup ke dalam pewarna. Dahulu kala, pewarnaan kain sasirangan dilakukan dengan tujuan tertentu, yaitu sebagai pelengkap terapi penyembuhan penyakit tertentu. (Annisa, 2014). Kain sasirangan memiliki motif-motif dan warna yang khas. Terdapat lebih dari 15 motif tradisional yang dimiliki oleh kain sasirangan, antara lain gigi haruan, bintang, naga balimbur dan masih banyak motif lain. (Rosyadi, 2017). Seperti dikutip dari hasil penelitian Ekawati, et al (2019), Motif-motif Sasirangan antara lain Gigi Haruan, Kembang Kacang, Hiris Gagatas, Kambang Sakiki, Tumpuk Manggis, Bintang, Kangkung Kaumbakan, Ombak Sinapur Karang, Bayam Raja, Kulat Kurikit, Hiris Pudak, Ular Lidi, Mayang Maurai, Naga
Balimbur, Banawati, Turun Dayang, Ramak Sahang, Gelombang dan Daun Katu. Kekhasan motif kain sasirangan apabila diolah maka akan memiliki keindahan tersendiri. Berikut contoh motif kain sasirangan:

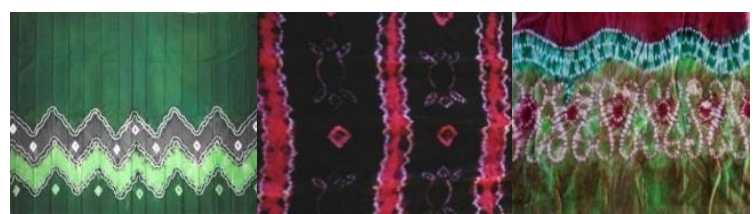

Gambar 1. Contoh-contoh Motif Kain Sasirangan

Motif-motif Kain Sasirangan memiliki bentuk dan corak yang khas. Pada Motifmotif Kain Sasirangan terdapat bentukbentuk geometris matematika, seperti segitiga, persegi, persegi panjang, jajar genjang, belah ketupat, dan lingkaran. Bentuk-bentuk tersebut membentuk polapola keteraturan. Pola-pola bentuk geometris yang terbentuk membentuk keindahan tersendiri. Ini merupakan salah satu contoh keindahan matematika yang ada dalam kehidupan sehari-hari. Hal ini sesuai dengan yang dinyatakan Sinclair (2006) bahwa "mathematics is one of the greatest cultural and intellectual achievements of humankind". Matematika 
adalah pencapaian intelektual dan budaya yang terbesar dari peradaban manusia. Keindahan matematika pada motif-motif kain sasirangan apabila di rangkai dengan sentuhan nilai estetika sedikit akan menghasilkan kain sasirangan yang bernilai jual tinggi. Hai ini karena nilai jual kain sasirangan salah satunya terletak pada motif-motif yang terdapat pada kain sasirangan tersebut.

Di Provinsi Kalimantan Selatan, terdapat banyak rumah industri pembuatan dan jahit kain sasirangan, seperti Sahabat sasirangan, Irma sasirangan, Iwan Sasirangan, Zahra Sasirangan dan masih banyak lagi. Berhamburnya industri pengerjaan kain sasirangan terjadi mengingat tingginya minat masyarakat Kalimantan Selatan memakai pakaian kain sasirangan dalam kehidupan sehari-hari, baik digunakan sebagai seragam kantor, gaun atau jenis pakaian lainnya. Banyak Instansi yang menggunakan kain sasirangan sebagai seragam, bahkan kain sasirangan menjadi pilihan bagi kalangan wanita yang ingin bergaya dengan memadumadankan kain sasirangan. Kain sasirangan menjadi seperti "Batik" nya Kalimantan Selatan. Menjamurnya usaha pembuatan dan jahit kain sasirangan menghasilkan limbah kain perca sasirangan. Kain sasirangan dijual per potong, tidak per meter. Satu potong kain sasirangan per potong umumnya berukuran 2 meter $\times 1,15$ meter. Harga kain sasirangan berkisar dari 80 ribu hingga ratusan ribu bahkan ada yang mencapai 1 juta tergantung motif dan 34 bahan yang digunakan. Bahan yang digunakan mulai dari katun, semi sutera sampai sutera. Kain sasirangan yang dijual per potong apabila diolah untuk satu jenis atasan atau kemeja ukuran sedang akan menyisakan kain-kain perca. Potonganpotongan kain perca sasirangan banyak dihasilkan di rumah-rumah industri atau di rumah-rumah jahit kain sasirangan.

Salah satu daerah di Kalimantan Selatan yang tingkat penggunaan kain sasirangannya cukup tinggi adalah Martapura. Martapura merupakan Ibu Kota Kabupaten Banjar yang merupakan Kabupaten dengan jumlah penduduk terbesar kedua di Kalimantan Selatan. Martapura merupakan daerah di Kalimantan Selatan yang memiliki kekhasan sendiri dari segi seni dan budaya, dan menjadi salah satu ikon Kalimantan Selatan. Dinamika kehidupan masyarakat Martapura terus berkembang menciptakan berbagai komunitas masyarakat dengan corak dan ciri khas tertentu, salah satunya masyarakat perumahan seribu. Dinamakan Perumahan Seribu, dikarenakan banyaknya rumah yang terdapat dikawasan kompleks perumahan bersubsidi tersebut.

Perumahan Seribu merupakan istilah yang sering digunakan untuk menamai sebuah komplek perumahan bersubsidi type 36, yaitu Komplek Mustika Griya Permai yang terletak di Desa Sungai Sipai, Kecamatan Martapura, Kabupaten Banjar, Provinsi Kalimantan Selatan. Dinamakan perumahan seribu karena hingga tahun 2018 ini sudah hampir lebih dari 2000 Jurnal Pengabdian Kepada Masyarakat MEDITEG Volume 4, Nomor 2, Desember 2019 Copyright @ 2019 Jurnal Pengabdian Kepada Masyarakat MEDITEG 
rumah yang ada di komplek ini dari blok $\mathrm{A}$ hingga blok $P$ yang terdiri atas beberapa RT. Setiap RT dapat meliputi dua Blok terdiri dari hampir 200 rumah. Wilayah ini memiliki potensi ekonomi yang besar dan dapat menjadi perkembangan pusat ekonomi mengingat jumlah penduduk yang besar. Akan tetapi, dikarenakan letaknya yang agak jauh dari pusat kota Martapura $( \pm 6 \mathrm{~km})$ dan sifat warga komplek yang cenderung agak individual dan kurang interaksi menyebabkan tingkat kreativitas dan daya beli masih rendah.

Potensi pasar dan ekonomi yang tinggi di Perumahan Seribu dapat ditingkatkan apabila warga masyarakat memiliki usaha yang kreatif dan memanfaatkan sumber daya yang ada, baik sumber daya alam dan sumber daya manusia. Kondisi di perumahan seribu saat ini, banyak Ibu-lbu rumah tangga yang menganggur di rumah dan memiliki banyak watu luang, namun ingin memperoleh penghasilan tambahan untuk membantu memenuhi keperluan keluarga. Kondisi ekonomi warga perumahan Seribu rata-rata termasuk kategori menengah ke bawah. Saat ini masih banyak Ibu-lbu yang kebingungan jika ingin memulai suatu usaha. Kebanyakan mereka tidak memiliki bekal keterampilan berwirausaha, yang meliputi mulai dari cara memanfaatkan peluang usaha, mengolah bahan-bahan yang tersedia menjadi sebuah produk hingga memasarkan produk yang dihasilkan. Apabila dibina dan diberi bekal keterampilan usaha, maka Ibu-Ibu akan menjadi lebih produktif. Mereka dapat mengisi waktu luang mereka guna menciptakan produk-produk menarik yang dapat meningkatkan penghasilan mereka.

Warga perumahan seribu yang dapat diberdayakan untuk meningkatkan produktivitasnya adalah Ibu-ibu yang tergabung dalam Kelompok Pengajian Langgar Nurul Iman. Ibu-ibu yang tergabung dalam Kelompok Pengajian Langgar Nurul Iman berjumlah sekitar 50 orang yang berusia rata-rata sekitar 35 45 tahun. Sebagian besar terdiri atas Ibu Rumah Tangga yang sehari-hari masih memiliki banyak waktu luang dan dapat memanfaatkannya dengan kegiatankegiatan yang positif dan produktif. IbuIbu cenderung memiliki waktu luang yang dapat dimanfaatkan, namun masih memiliki keterbatasan wawasan, keterampilan dan pengalaman serta modal ketika akan memulai suatu usaha.

Berdasarkan uraian di atas, dapat diidentifikasi masalah yang perlu ditanggulangi dalam upaya memberdayakan Ibu-ibu warga perumahan seribu, Desa Sungai Sipai agar lebih produktif yaitu: (1) Belum ada peran aktif dalam mengembangkan potensi Sumber daya yang ada di daerah untuk meningkatkan taraf ekonomi masyarakat, sementara Perumahan Seribu memiliki Potensi yang besar salah satunya adalah dari segi sumber daya manusia, (2) Kurangnya Informasi mengenai peluagpeluang bisnis rumahan yang dapat dikembangkan, 
keterampilan dan kreativitas yang dimiliki masyarakat, terutama Ibu-Ibu dalam memanfaatkan bahan-bahan yang ada di sekitar mereka dan (4) Kurangnya permodalan usaha yang dimiliki, karena sebagian besar masyarakat perumahan Seribu termasuk golongan ekonomi menengah ke bawah.

Melihat permasalahan yang ada yaitu melimpahnya limbah kain perca sasirangan dan perlunya membekali IbuIbu warga perumahan seribu dengan keterampilan berwirausaha mulai dari cara mengolah hingga memasarkan produk yang dihasilkan, maka solusi yang dapat ditawarkan adalah dengan menciptakan usaha kreatif bagi para Ibu-Ibu yang dapat meningkatkan pendapatan sekaligus memanfaatkan limbah kain perca sasirangan yang ada. Keinginan yang kuat untuk meingkatkan perekenomian keluarga tidak didukung kemampuan atau kreativitas yang dimiliki. Potensi yang dimiliki Ibu-Ibu warga perumahan Seribu saat ini masih dapat terus diberdayakan untuk menghasilkan sesuatu yang produktif.

Peluang usaha yang dapat dimanfaatkan oleh Ibu-lbu adalah yang dalam pengerjaannya dapat memanfaatkan waktu luang yang dimiliki, dapat dikerjakan secara bersama-sama dengan modal yang tidak terlalu besar.Solusi yang ditawarkan adalah alternatif usaha kerajinan tangan kain perca sasirangan.Usaha kerajinan tangan tidak memerlukan modal yang relatif besar dan dapat menggunakan bahan36 bahanyang banyak tersedia di lapangan, namun apabila dikemas dan dilakukan dengan tekun dan kreatif dapat menghasilkan produk yang bernilai jual tinggi. Banyak usaha berbasis keterampilan tergabung dalam kelompok Usaha Kecil Menengah (UKM) dan mampu menyerap tenaga kerja. Hal ini membuktikan industri ini bermanfaat dan besar andilnya dalam meningkatkan perekonomian.(Zulkarnaen, 2008).

Kain-kain Perca Sasirangan dapat diolah menjadi produk-produk yang sering dipakai dikalangan masyarakat dan bernilai jual tinggi dan memiliki kekhasan Kalimantan Selatan. Motif kain sasirangan yang unik akan menjadikan produk-produk yang dihasilkan menjadi bernilai daya jual tinggi. Kain-kain perca sasirangan dapat dimanfaatkan untuk diolah menjadi produk-produk kerajinan tangan yang dapat digunakan dalam kehidupan seharihari, seperti tas, dompet, kantong HP, sarung bantal kursi, taplak meja, peci, gantungan kunci, aksesoris seperti kalung, bros dan lain-lain. Kain-kain Perca diantaranya dapat diubah menjadi aksesori seperti aneka hiasan rambut, gelang, kalung, bros dan cincin. (Subiakto, 2009). Usaha membuat kreasi bros dapat menjadi alternatif usaha kerajinan tangan, mengingat bahannya mudah didapat dan tidak memerlukan modal yang besar. Selain Pangsa pasarnya yang masih luas, trend bros akan selalu berkembang dari masa ke masa. (Etty \& Yusfidar, 2004).

Melihat Peluang Usaha dan Potensi yang dimiliki Ibu-Ibu warga perumahan Jurnal Pengabdian Kepada Masyarakat MEDITEG Volume 4, Nomor 2, Desember 2019 Copyright @ 2019 Jurnal Pengabdian Kepada Masyarakat MEDITEG 
Seribu saat ini, maka perlu dilakukan upaya pemberdayaan Ibu-lbu warga Perumahan Seribu untuk menghasilkan sesuatu yang produktif. Salah satu caranya yaitu menciptakan Usaha Kerajian Kain Perca Sasirangan menjadi produkproduk menarik yang dapat dipasarkan dan memiliki daya jual tinggi. Oleh karena itu, untuk membekali wawasan dan keterampilan pengolahan usaha kerajinan kain perca sasirangan, maka akan dilakukan kegiatan Pengabdian Kepada Masyarakat berupa Pelatihan dan Pendampingan pengolahan Kerajinan Tangan Kain Perca Sasirangan bagi Ibu-Ibu warga Perumahan Seribu.

\section{Metode}

Metode Pelaksanaan pada Program Pengabdian Kepada Masyarakat ini adalah pelatihan atau penyuluhan dalam bentuk ceramah, diskusi dan demonstrasi (praktik). Pelatihan yang dilakukan adalah pelatihan mengolah limbah kain perca sasirangan menjadi produk-produk seperti tas, dompet, kantong HP, sarung bantal, aksesoris, bros dan kopiah atau peci. Mitra pada kegaitan ini adalah Ibu-lbu anggota kelompok pengajian Langgar Nurul Iman RT 27 RW 01, Desa Sungai Sipai, Martapura. Kegiatan dilakukan dalam beberapa tahap, yaitu (1) Persiapan Kelengkapan Administrasi dan Bahan, (2) Observasi dan Survei Lapangan, (3) Pelaksanaan Kegiatan Pelatihan dan (4) Evaluasi Kegiatan. Bahan utama dalam kegiatan ini adalah limbah kain perca sasirangan. Pelatihan akan diberikan kepada mitra yaitu sebanyak 7 (tujuh) kali pertemuan.

Kegiatan pelatihan dimulai dari pengenalan usaha kerajinan tangan kain perca sasirangan, penjelasan produkproduk apa saja yang dapat dihasilkan, dan dimana dapat memperoleh limbah kain perca sairangan. Pertemuan pertama berupa knowledge sharing dan lebih bertujuan untuk membuka wawasan dan memotivasi peserta. Pada pertemuan berikutnya, para peserta berlatih atau melakukan praktik secara mandiri atau berkelompok keterampilan kerajinan kain perca sasiragan di bawah bimbingan nara sumber atau instruktur menggunakan bahan-bahan yang telah disediakan. Pada pertemuan ini, produk-produk yang akan dihasilkan yaitu tas, Dompet, kantong HP, Sarung Bantal Kursi, Taplak Meja, Kopiah/ peci, bros dan aksesoris lainnya. Pertemuan ketiga masih memberi pelatihan kepada peserta membuat berbagai kerajinan tangan kain perca sasirangan, tetapi lebih memfokuskan pada produk-produk aksesoris, seperti kalung, gantungan kunci, dan bros yang pengerjaannya tidak memerlukan peralatan yang besar seperti mesin jahit. Pertemuan keempat memberikan kesempatan kepada Ibu-Ibu melakukan praktik sendiri membuat kerajian kain perca sasirangan sesuai dengan materi pelatihan yang telah diberikan sebelumnya. Pertemuan kelima membahas cara pengemasan produk- 
produk yang dihasilkan dan memberikan merk agar kemasan produk yang dihasilkan menarik. Pertemuan keenam membahas cara pemasaran produk yang dihasilkan, baik secara offline maupun online. Pertemuan ketujuh memberikan kesempatan kepada peserta melakukan kegiatan simulasi dari mulai dari pengolahan, pengemasan, pemberian merk dan pemasaran dan memberikan pemaparan tentang motivasi agar usaha kerajinan tangan ini dapat dilakukan secara berkelanjutan

\section{HASIL DAN PEMBAHASAN}

Kegiatan diawali dari Persiapan Kelengkapan Administrasi dan Bahan. Kegiatan ini dilakukan pada bulan Maret 2019. Tim pengabdian menyiapkan bahan dan Alat yang diperlukan seperti mesin jahit, lem tembak, gunting, jarum, benang, pita, mutiasa sintetis, berbagai macam kain dan lain sebagainya. Pembelian Alat dan Bahan dilakukan di Toko-toko peralatan jahit dan mesin jahit di Martapura. Selain itu tim PKM juga menyiapkan nara sumber atau instruktur yang berkompeten untuk memberikan pengetahuan dan pelatihan yang dibutuhkan.

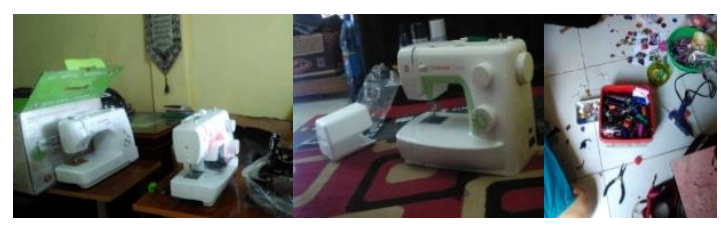

Gambar 2. Mesin Jahit dan Peralatan untuk Pelatihan
Bahan utama kegiatan ini adalah kain perca sasirangan. Kain perca sasirangan dibeli pada penjahit salah satu brand Sasirangan terkenal yaitu "Sahabat Sasirangan" yang ada di Martapura. Selain itu bahan utama pembuatan kerajinan ini adalah kain flanel, kain satin, dan kain kapas. Bahan-bahan ini banyak terdapat dipasaran dan mudah didapatkan, selain itu harganya cukup terjangkau, sehingga dapat dipastikan tidak akan mengalami kesulitan dalam mendapatkan bahan.
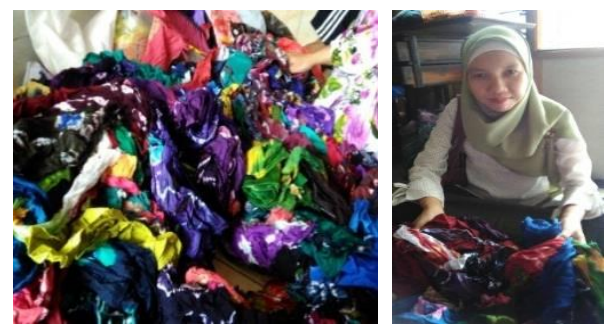

Gambar 3. Proses Pembelian Bahan Kain Perca Sasirangan

Kegiatan ini diikuti oleh kelompok ibuibu pengajian langgar nurul iman perumahan seribu kabupaten Martapura yang berjumlah 35 orang. Dalam setiap kegiatan terlihat antusias dari ibu-ibu. Hal ini bisa dilihat dari jumlah hadir yang selalu memenuhi target. Selain itu antusias ibuibu ini bisa dilihat dari semangatnya dalam menyelesaikan setiap tugas yang diberikan oleh instruktur untuk menyelesaikan berbagai macam bentuk kerajinan dari kain perca sasirangan.

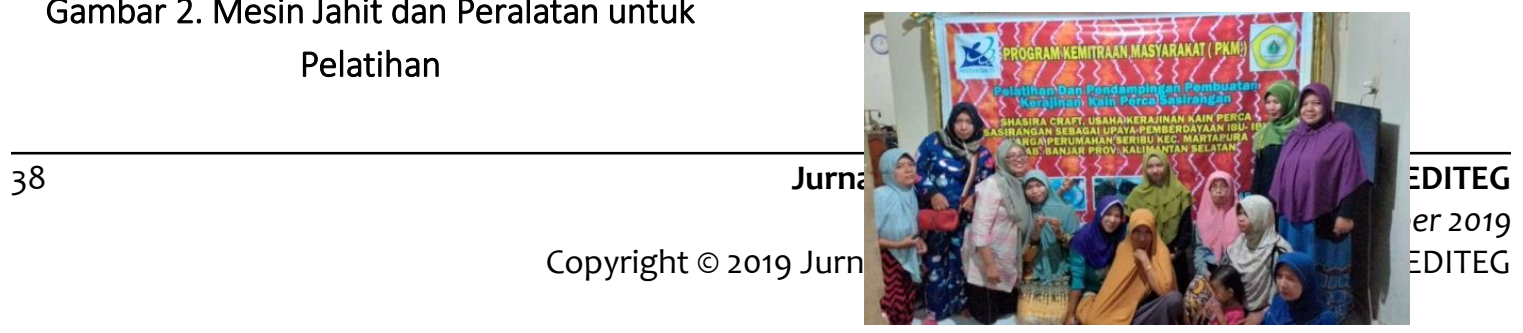


Gambar 4. Peserta Kegiatan Pelatihan

Kegiatan pelatihan dilaksanakan sebanyak 7 kali pertemuan, dengan rincian materi sebagai berikut:

Tabel 1. Rincian Materi per pertemuan

\begin{tabular}{|c|c|}
\hline Pertemuan & Materi \\
\hline I & $\begin{array}{l}\text { Knowledge Sharing, } \\
\text { Pengenalan Usaha Kerajian } \\
\text { Kain Perca Sasirangan }\end{array}$ \\
\hline II & $\begin{array}{l}\text { Praktik Pengolahan Produk } \\
\text { Kerajinan Kain Perca } \\
\text { Sasirangan (Bros) }\end{array}$ \\
\hline III & $\begin{array}{l}\text { Praktik Pengolahan Produk } \\
\text { Kerajinan Kain Perca } \\
\text { Sasirangan (Tas, dompet, } \\
\text { dan lain-lain) }\end{array}$ \\
\hline IV & 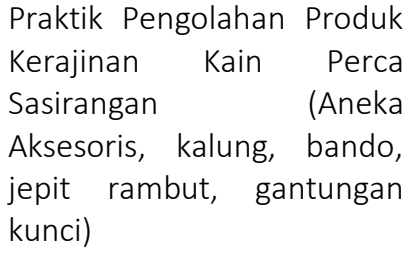 \\
\hline V & $\begin{array}{l}\text { Praktik Pengolahan Produk } \\
\text { Kerajinan Kain Perca } \\
\text { Sasirangan (Toples Cantik) }\end{array}$ \\
\hline VI & $\begin{array}{l}\text { Praktik Pengemasan dan } \\
\text { Pemberian Label Produk }\end{array}$ \\
\hline VII & $\begin{array}{l}\text { Teknik-teknik pemasaran } \\
\text { secara online dan offline }\end{array}$ \\
\hline
\end{tabular}

Hasil dari setiap pertemuan, Ibu-Ibu termotivasi untuk melakukan kegiatan wirausaha dan memiliki minat dalam menghasilkan produk-produk dari limbah kain perca sasirangan. Peserta yang merupakan Ibu-lbu warga perumahan Seribu dengan tekun mengikuti pelahitan pada setiap pertemuannya. Peserta antusias mengikuti setiap kegiatan pelatihan. Mereka memiliki kepuasan tersendiri apabila mampu menghasilkan produk-produk dengan tangan mereka sendiri.

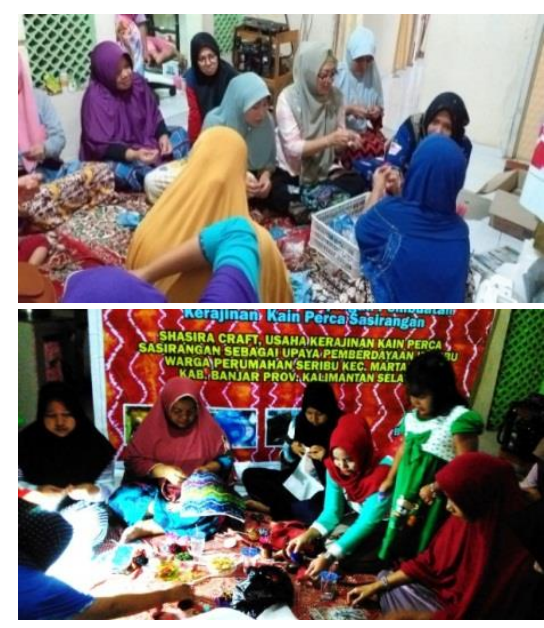

\section{Gambar 5.Peserta melakukan kegiatan Praktik}

Pada setiap kegiatan, peserta juga menggunakan peralatan yang tersedia mulai dari gunting, jarum tangan, benang sampai mesin jahit untuk mengolah kain perca sasirangan. Peserta mengikuti seluruh instruksi yang diberikan selama kegiatan Pelatihan dengan baik, mulai dari membuat pola, menjahit pola hingga menjahit secara manual atau menggunakan mesit jahit sampai jadi sebuah produk yang diinginkan.
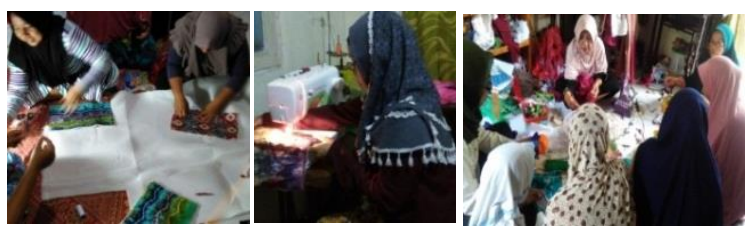

Gambar 6. Peserta Mencetak Pola Dan Menjahit Pola Menggunakan Mesin Jahit Dan Peralatan Lainnya 
Hasil dari 7 kali pertemuan sudah bisa dilihat bahwa ibu-ibu pengajian telah memiliki jenis keterampilan dalam membuat berbagai produk kerajianan tangan dari kain perca sasirangan yaitu bros, tas tangan, kantong HP, berbagai aksesoris seperti bando, kalung, bunga, jepit rambut, dan menghias toples cantik dengan kain perca sasirangan. Berikut adalah berbagai produk yang dihasilkan oleh Ibu-lbu kelompok Yasinan Mushala Nurul Iman selama Kegiatan pelatihan.
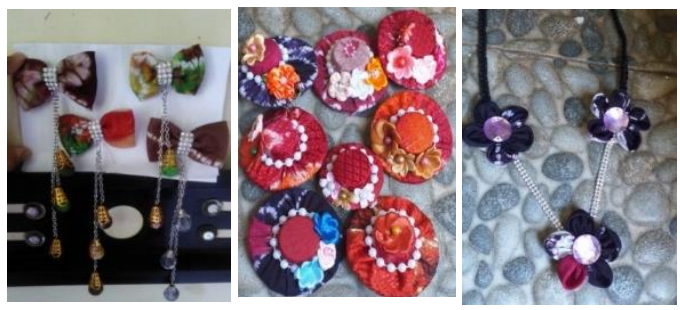

Gambar 7. Berbagai Produk Aksesoris Hasil Karya Peserta

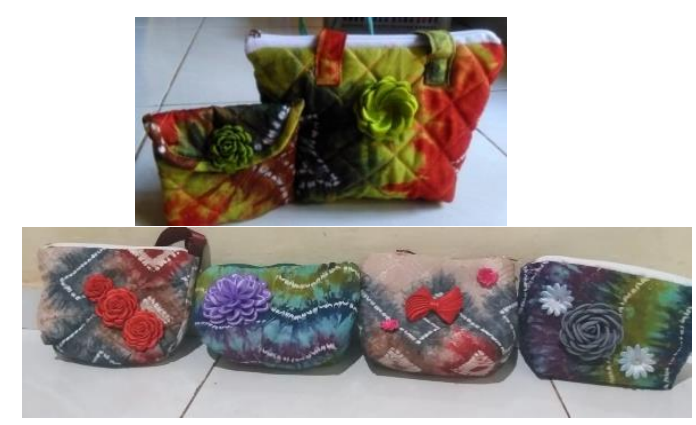

Gambar 8. Aneka Produk Tas dari Kain Perca Sasirangan

Produk-Produk yang dihasilkan kemudian dikemas menggunakan plastic kemasan dan diberi label nama merk. Pendesaian Label dilakukan menggunakan jasa desain menggunakan bantuan komputer. Label merk menggunakan nama "Shasira Craft". Selain menghasilkan produk-produk dari kain perca sasirangan, 40 kegiatan pelatihan ini menunculkan semangat untuk belajar dari Ibu-lbu peserta. Hal ini terlihat dari banyaknya pertanyaan mengenai waktu pertemuan selanjutnya, juga mengenai teknik pemasaran sehingga kerajinan kain perca sasirangan mampu mendatangkan income bagi mereka. Ibu-ibu yasinan sebagian telah menjual dari kerajinan tangan dan mereka sangat bersemangat, karena kerajinan yang mereka bikin laku. Hal yang paling penting adalah tumbuhnya minat berwirausaha pada diri Ibu-lbu yaitu dengan memanfaatkan barang-barang yang ada dan keterampilan yang telah dimiliki.

\section{Penutup}

Pengabdian masyarakat ini sangat penting dilaksanakan, karena begitu besar dampaknya bagi masyarakat dalam pengembangan potensi diri sehingga masyarakat mampu memiliki kemandirian dalam bidang ekonomi. Selain itu masyarakat juga dididik untuk mampu melihat peluang disekitar dengan memanfaatkan bahan-bahan yang berlimpah yakni kain perca sasirangan menjadi produk yang memiliki nilai ekonomi, sehingga memberikan peluang dalam pertumbuhan UKM bagi masyarakat. Kegiatan pengabdian ini tentunya berdampak positif juga bagi tim yang merupakan praktisi akademisi yang dituntut untuk mampu melaksanakan tridarma perguruan tinggi sebagai salah satu dari kewajiban seorang dosen. Nilai positif lain adalah dosen mampu lebih Jurnal Pengabdian Kepada Masyarakat MEDITEG Volume 4, Nomor 2, Desember 2019 Copyright $\odot 2019$ Jurnal Pengabdian Kepada Masyarakat MEDITEG 
dekat dengan masyarakat dan bekerjasama dalam membangan bangsa melalui pendidikan masyarakat.

\section{UCAPAN TERIMA KASIH}

Terima Kasih kami ucapkan kepada Kementrian Riset, Teknologi dan Pendidikan Tinggi yang telah mendanai kegiatan ini dan Ibu-Ibu Kelompok Pengajian Mushala Nurul Iman, Perumahan Seribu, Martapura yang telah berpartisipasi aktif pada setiap kegiatan, serta kepada berbagai pihak yang telah membantu terselenggaranya kegiatan.

\section{Daftar Pustaka}

Annisa, Y. (2014). Lebih Jauh Mengenal Batik Sasirangan. Bogor. Optima.

Ekawati, et.al. (2019). Geometrical Concepts on Batik Sasirangan.Journal of Physics, presented on $5^{\text {th }}$ International Symposium on Mathematics Education and Innovation (ISMEI).

Etty, Laksmiwati dan Alida Yusfidar. (2004). Bros dari Bunga Pita. Surabaya: Tiara Aksara.

Rosyadi, M. D. (2017). Pengenalan Motif Dasar Pada Kain Sasirangan Menggunakan Metode Template Matching. Technologia, 2 (2), AprilJuni 2017.

Sinclair, N. (2006). Mathematics and Beauty, Aesthetic Approaches to Teaching Children. London: Teachers College Press.
Subiakto, Monica. (2009). Aksesoris Cantik dari Kain Katun. Jakarta: Demedia Pustaka.

Zulkarnaen, Yossi. (2009). Kreasi Cantik Sulam Kombinasi. Jakarta: Kriya Pustaka

\section{Riwayat Hidup PENULIS}

Mayang Gadih Ranti, S.Si, M.Pd

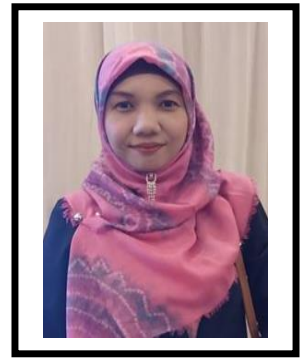

Lahir di Yogyakarta, 7 Agustus 1987. Staf pengajar di STKIP PGRI Banjarmasin. Studi S1 Matematika Universitas Lambung Mangkurat, Banjarbaru, lulus tahun 2008; S2 Pendidikan Matematika Universitas Negeri Yogyakarta, lulus tahun 2012. 